\title{
A NEED FOR HOLISTIC APPROACH TO THE OCCUPATIONAL HEALTH DEVELOPING (IN SERBIA)
}

MIRJANA ARANDJELOVIC

The University of Nis, Nis, Serbia

Faculty of Medicine

The Institute for Workers' Health Protection, Nis, Serbia

\begin{abstract}
Countries in transition, such as Serbia, have been going through obligatory system reforms, including the reform of the healthcare system. As a rule, occupational health becomes marginalized by the authorities who decide on medical care. In spite of the fact that this branch of medicine cares for working population that mostly carries the burden of transition, when material situation equals the existential minimum, its potentials are not recognized. On the other hand, the World Health Organization makes a remark that such population's health is undermined now more than ever, and adopts a binding global plan for member countries and their experts in occupational health to take urgent measures for overall working people's health according to their needs. It seems that former work method of biomedicine specialists could not realize such ambition. This paper discusses the possibilities of occupational health future orientation toward holistic medicine, for the sake of workers' well-being and better quality of their lives, then creation of more humane society and vocational affirmation. Health promotion at workplace and salutogenic concept may have crucial roles. This concept is a huge challenge for academic public and vocational practitioners in poor countries in transition that are already burdened with the current economic and financial crisis. Each in their own way, helped by self-education and education, without big material investments, together they may take their countries to the road of health, the road still rarely taken, yet more secure.
\end{abstract}

Key words:

Holistic medicine, Quality of life, Philosophy of medicine, Occupational health, Salutogenesis,

Health promotion at workplace, Transition

\section{INTRODUCTION}

Poor countries in transition that are experiencing the current financial crisis, zealous to make visible and rapid changes, have made the moves that in the long run have quite the opposite effects, in many different spheres of life. The health care system is usually affected first. Since the countries want to cut the health care expenditure, the health and well-being of working population, which is supposed to bear the burden of transition, have been directed to businessmen and employers that do not have capital, and do business mostly by trading in kind. Their lack of consciousness of how important it is to invest in the protection of the working people's health, and the lack of legislation which should be binding for them, are additional hindrances. State authorities do not recognize occupational health as an important link in the health care system they have been reforming, in spite of dramatic changes occurring in the area of work and severe consequences to workers' health. They also refuse to recognize the fact that workplaces are places where workers spend most of their

Received: January 17, 2011. Accepted: June 27, 2011.

Address reprint request to Z. Djindjić Blvd. 81, 18000 Niš, Serbia (e-mail: amima@eunet.rs). 
awake time, and where they and their health can be affected in large scales.

Serbia is not an exception. Being a country in transition, after a turmoil that has been going on for a while, about the future of occupational health as a branch, some logical questions have been put forward: does it have a future? If it does, which is the best way to develop it? The author of this paper deems one thing to be for sure: silent acceptance of the status quo where occupational health is today can only worsen its position. Therefore, development directed properly is possible only if we have the perspective of how occupational health should look like tomorrow. Crucial understanding of the text that has been chosen to be a motto of the profession at the global level, "A healthy worker at a healthy workplace" [1], thus, has to be the basic inspiration for all people who dare take the plunge into the topic.

It seems that even the World Health Organization (WHO) followed exactly the same determinant when it decided to prepare a Global action plan for further development of the protection of the working people's health, applicable to all member countries in the period of 2008-2017, with priority tasks in the period of 2009-2012, after it had had an insight into the results of regular monitoring of working population's health in the world, which were pretty alarming $[1,2]$. Such plan was presented to the representatives of Southeast European workers' health regional network, which Serbia also belongs to, during the meeting held in June this year in Croatia [3] (the plan was adjusted to the earlier WHO's recommendations and adopted directives). Therefore, a professional vision of occupational health has to be supported by the current plan of the WHO and the objectives it defines. The detailed guidelines for concrete definition of its future actions in that direction should be looked for in the definition (WHO, 2009) [2] related to the notion of "healthy workplace" which reads: "A healthy workplace is a place where workers and employers cooperate and continually improve the process of protecting and promoting health, safety and workers' well-being for the sake of sustainable development of a workplace, all of which is based on identified needs, taking into account the following: health and safety in physical work environment; health, safety and well-being in psycho-social work environment, including organization of work and culture at a workplace; personal health resources of the employed, and the way a community participates with the aim to improve the health of workers, their families and other community members".

If we agree that basic stimuli of "Occupational health tomorrow" in Serbia are determined by the organization that directs the activities related to health at global level (WHO), then, it can be concluded that the basic activity of occupational health in future, as up till now, will be oriented to risk assessment in the physical environment and activities directed to worker safety, the prevention of occupational diseases and injuries. It is certain that stateof-the-art technology of contemporary business does give a hint on a possibility of new risk occurrence (e.g., bio- and nanomaterials, on-line working, etc.), which will unquestionably condition an inevitable modification of the existing methodology for risks to be precisely detected, but it can only be a great challenge to the vocation in times to come, not a hindrance at all. The development of vocation in this direction is indisputably important, but it cannot be sufficient as such [1-3].

What gives the meaning and justifies the necessity of existence of occupational health is definitely a Man a worker, and concern for his/her health. Moreover, occupational health, even according to the definition, is a state of complete physical, mental and social wellbeing at work - not only the absence of diseases or disability acquired at work or elsewhere. Thus, we need to clarify the notion of physical well-being: it suggests optimal functioning of all physiological systems and organs; mental well-being, on the other hand, implies the possibility of making choices, progress, communication, 
the right to information and the ability to meet refusals; the emotional mental well-being implies comprehension, recognition and emotion control, whereas the spiritual well-being means the development of awareness of the point of life and its values.

Health, as well as life, is a dynamic and complex process and it is not possible to grasp it apart from the religion, social, economic, political, cultural or any other influences. Modern pace of life, the development of new technologies, the internet, the large number of information we need to process, obliteration of clear borders between time (working hours) and space (workplace), all largely shape work characteristics, hence the needs of a modern man [4,5]. Yet, a limited ability of adaptation and inability to satisfy the needs of the workers, or the absence of the meaning and point of life, create tension and inner dissatisfaction, i.e. stress in workers, that progressively damage their health and cause an enormous increase in psychosomatic disorders. The phenomena of burnout, mobbing, violence at work, etc. reduce additionally the quality of their lives. Current financial crisis enhances the intensity of negative connotation of modern business doing, particularly accentuating, in psychological sense, burdening a human being as a carrier of work process [6-9].

The evolution of society has led to evolution of consciousness in people, changing their attitude toward health and illnesses greatly. A prerequisite for health is satisfaction with life and the possibility of self-realization. Therefore, the perception of health nowadays equals the quality of life of an individual, whereas illness is a consequence of poor quality of life and imbalance at the level of basic human needs. There is scientific evidence that physical health of a human being is directly proportionate to emotions, and it is conditioned by thinking. That is why health and work psychology, as the parts of health science, and well-being of the employed have become strategically very important disciplines when it comes to personal existence and development, the development of work organizations, even national economies that gain in importance when the crisis is globally escalating [10-15].

In this paper, the individual's and public's health is viewed as a dynamic process, but not independent of other dynamic processes (e.g., economy, politics) that are all part of a much bigger process. Furthermore, it is argued that it is not merely sufficient to account for all known factors to be holistic. In this paper, the holistic conceptual model is illustrated, using public health as the central issue.

\section{TODAY IS TOMORROW}

Occupational health, as a preventive branch of medicine, must as soon as possible demonstrate the ability of answering the challenge it has been facing. At the same time, this is an opportunity to prove necessity of its existence within the state healthcare system. This way, an appropriate practical reaction may turn the vocational problem into an opportunity. The existence of occupational health is mostly conditioned by how much it is capable of influencing the quality of lives of workers and employers it is serving $[16,17]$. That is why tomorrow is already today for vocation such as occupational health. In a nutshell, tomorrow depends on how much it is present today.

In this sense, anti-stress management program is the first and urgent preventative activity such vocation should carry out. If truth be told, the need for this type of engagement exists ever since the Law on obligatory risk assessment at work has been adopted for every employer in the country. At the end of the official act, the results of such assessment in most cases contained, among all, a verified harmful agent: stress at workplace [18]. Thus, orientation of the occupational health to this direction has become a feedback to real situation, and quick reaction to WHO's recommendations presented within the Global plan, which as a whole has only one objective: consideration of workers' health in its entirety, not only related to occupational health. As this is a complex phenomenon, a hard 
and thorough work is required, which implies adoption of standardized generic instruments for testing Work Ability Index (WAI), the quality of life, burnout, mobbing, $\mathrm{Hu}-$ man Work Index, etc. [1-3].

WHO's Global plan is certainly binding for all member countries, yet it seems to give considerable freedom to each individual country to define its own objectives. At this particular moment, if occupational health as vocation in Serbia is capable of recognizing such freedom not as "freedom from", but "freedom for", and qualify enough to meet the requirements and needs of the workers as they are, it will, by all means, give Serbia the chance to develop significantly as a humane society. A workplace is a suitable ground for realization of such idea, a place where people spend most of their awake time, and the area which can be influenced most, for common good and to mutual satisfaction. Hence, freedom refers to whether the vocation in the upcoming period will be waiting for guidelines of already directed development as recommended by the WHO's Global plan, which is undoubtedly good, and just follow it, or, they will be paving the way to the common goal with their own creativity, knowledge, experience, skills. One has to admit that it would be a zigzag road to take; it requires the energy and loads of knowledge, typical for people who are dedicated to their profession. The index of success of vocation moving toward this direction would be the Human Work Index, considered carefully in the above-mentioned document - WHO's Global plan, which the profession should implement as the instrument in everyday work $[19,20]$.

The freedom of choice, however, without the sense of responsibility and respect for the basic moral/ethical principles rarely leads to desired goal. This is being mentioned now because the profession of occupational health has to take huge responsibility for working culture in Serbia, no matter how hard it is to discuss it now, and we know that there is not enough political willingness and financial support to take culture even into consideration.
The connection between health, life quality and culture needs not be questioned. Teaching others - in this case, the employers, owners of small and medium-sized companies, their employees, craftsmen - any culture, even working culture, is a complex task; it is not easy at all. It is a process which needs to be done according to certain rules [21]. Occupational health experts that are familiar with the code of medical profession, and that have officially adopted the professional code, therefore have the task to transfer their experience to all companies and legal entities whose health they take care of, so that the companies and legal entities, too, can adopt their own code of behaviour [22,23]. However, the code of behaviour and business doing is more than a code, it certainly is transmitted best (if not solely) by a personal example that includes the art of dialogue, communication, assertive behaviour, mutual understanding and respect. These are the characteristics one should constantly master within their own profession, through continual education in the area of social and emotional intelligence, non-verbal communication, neuro-linguistic perception, etc. Constant improving of our own code of behaviour is the only way the code of behaviour of management and employees can be altered substantially, which in the end defines the level of culture at work. This is the only way that occupational health can become an example of good practice to those for whom it exists [24]. Holistically viewed, it doesn't matter how good a stress management may be in a workplace if the management culture is one of bullying [25,26]. There is evidence that adoption and development of new management philosophy, developed as it has been described, and implementation of the co-manager position, have resulted in positive work atmosphere where stress is reduced to the lowest possible level. Co-managers (i.e., experts in work organization management in charge of workers' health) may and should be recruited from the profession of occupational health, tomorrow [27]. 


\section{OCCUPATIONAL HEALTH $\rightarrow$ WORKERS HEALTH}

Official health, biomedicine, directed to concrete illnesses and their treatment by medications, in spite of fantastic development of the pharmaceutical industry in the previous decades, almost from the very beginning has not turned out to be enough, regarding the perception of human health. Although there are preventative branches of medicine, health promotions through the institutes for public health, health education through individual and group work within wider medical disciplines directed to reduction of health risks, the hiatus between sickness and health has been deepening day by day. Inability to control stress that modern life generates, contributes to gap widening even more. Since the dawn of time, when pathogenic medicine was conceived, scientific world has been trying to find out other paths to health as a whole, for everybody has long ago agreed that health is much more than the absence of physical illness. As a result of mutual cooperation and multidisciplinary approach to the matter, holistic medicine emerged (Greek, cholos - complete, whole). It deals with substantial human values, recognition of the purpose of life in individuals, as the links missing in the biomedicine chain, on the road to ever-sought-for health as a whole [28-34].

Holistic medicine is the one displaying ambition to cure patient's character, no matter how difficult it is to understand such concept [35]. It is the kind of medicine where doctors deal with virtues of a human being, their talent, recognition of the purpose of their lives on the road to self-realization, the lack of which make life unbearable. Let me remind you, life satisfaction is prerequisite for health. This is a type of medicine preaching the positive concept of all therapeutic procedures, either healing or treatment, for the sake of better quality of life, as a measure of perception of modern age Man's health. A human being, a patient, has a crucial role and responsibility for the outcome of treatment, since holistic medicine is the medicine of self-healing. The insight they have while in the process of healing (or prevention, for that matter), perception, understanding, acceptance, ability to connect, gained experience related to that, and practical realization of newly-formed attitudes toward life, are major paths to the cure. A holistic doctor should just give directions to people and help them recognize the key events in their lives that were lived out improperly, but have established their character and behaviour which largely contribute to the state of sickness. Of course, they have to be capable of meeting the requirements of the position they have in the holistic health concept. Their competence is, therefore, determined by their characters, the ability to give themselves to others spiritually, and by morality, i.e. the ethical code. That is because they envisage the encounter of doctor and patient in holistic therapy as the encounter of two souls on the path to inner peace. This is a process, not giving out prescriptions and medicaments, waiting for them to take effect, although the above-mentioned process implies that, too. This is a process that certainly embarks upon philosophy and psychology of life and in many aspects resembles a kind of art. Yet, health, the gist of it, is in a way a logical consequence of the art of living [36-47]. Therefore, holistic medicine cannot be the same as medicine now. It takes a critical mass of conscious and educated doctors (and not only them) who will act according to complete holism. Occupational health doctors have to be aware of that. The following cannot be omitted: alternative medicine also aspires to be an indispensable part of health as a whole. Sure there is biomedicine which is irreplaceable where it is necessary. Integrative promotion of health can be ultimately decisive for this story, i.e. it can bridge the gap between sickness and health, even the gap between holistic medicine and biomedicine. A positive salutogenic concept of health promotion seems to be promising mostly regarding the success of such aspirations $[48,49]$.

It is not possible to observe health promotion outside the described concept of contemporary medical and scientific 
tendencies on their way to health as a whole, for it stands for their practical realization. Health promotion at work is an indispensable part of the whole, and according to WHO's Global plan, an obligatory activity of occupational health as vocation. The scientific area of occupational health today and its implementation tomorrow must be guided by the described global tendencies. It implies the necessity of structural re-orientation of vocation, from being directed to health in connection with work, to health as a whole (Occupational health $\rightarrow$ Workers health). This seems to be the only path that promises survival of the vocation, even realization of its vision, "A healthy worker at a healthy workplace", regardless of how distant it looks like at the moment [1-3].

\section{WORKPLACE HEALTH PROMOTION}

Workplace Health Promotion includes the combined efforts of employers, employees and the society to improve health and well-being of the people at work (Luxembourg Declaration of 1997). Health (life) promotion in wider context implies the process which enables individuals, groups of people or the whole society to increase health control and improve health in physical, mental, social and spiritual sense. The very process should be supported by creation of environment in natural and social sense, where people could identify their internal and external resources, so that they could exploit them multiply, to make their wishes come true, satisfy their needs, make their lives meaningful and be able to accept or alter their environment for the sake of health promotion [50]. When it comes to workplace health promotion in Serbia, in the previous period, occupational health mostly dealt with health education, where workers and their employers had a very passive role regarding the issue of our interest. Nowadays, health promotion is based on the dialogue and active participation of all subjects and has long ago surpassed the activities such as promotions of healthy life-style. Hence, vocational activities have to be directed to development of workers' health literacy. Better health literacy is the key to the positive outcome of health education [51,52].

Health literacy denotes personal cognitive and social skills that determine the ability of an individual to get understand and use information to improve and maintain health. Classification to basic, functional, interactive and critical health literacy indicates that workers need to have a minimum level of functional health literacy within the framework of workers' health protection, so that they are able to exercise their right to health care. It is an obligatory step toward sharp inner perception of health determinants, as the highest goal of health protection in general, even workplace health promotion. According to the latest findings, this is the only possible way to health as a whole and quality life; together with full awareness of the wide spectrum of many inevitable changes in all spheres of life outside work that life puts forward. Moving in this direction demands appropriate training within vocation, through the programs of continuous education. A handbook for workers is vocation's duty on this road [53].

\section{SALUTOGENESIS}

In the 70's of the previous century a different approach to health was developed, the one that primarily emphasized the factors that make it possible for people to maintain health, not so much the factors that cause diseases. As a counterpart to pathogenic orientation, this approach was called salutogenic, and one of the pioneers and the most important advocate of such approach was Aaron Antonovsky (1979) [54]. In his opinion, stress is a natural phenomenon in life. It is individual's inability to cope with it that may lead to the development of disease. Stress mechanism development and specific, yet simple description of possible stress-coping procedures that a human being can adopt or learn through health promotion, were the initial inspiration for numerous scientific areas of 
research, such as: philosophy, sociology, psychology, economics, medicine, pioneering holistic perspective of human health. The climax of helplessness of basic medicine in stress flood - "the existential vacuum" - resulted in rebirth of the salutogenic concept [55].

Within the framework of salutogenic health promotion model, the leading role in fighting stress is given to the sense of coherence, i.e. a dynamic sense of safety, which implies that events in people's inner and outer surroundings are predictable and explainable, and that people have their inner resources (experience) at disposal which can be utilized to fight the tension cumulating when such unpleasant events occur, thus, these events need to be perceived as challenges to be met, not problems. It is assumed that a stronger sense of coherence enables individuals to activate an efficient mechanism of confrontation in stress situations, which helps them to draw near health on the continuum. A low sense of coherence disables activation of appropriate resources, which leads to poorer stress management, thus increasing the probability of health deterioration. This is a process that needs to be developed from the moment we are born, during child upbringing, and yet it can be taught to adults in the process of health promotion and holistic medicine therapy [56]. This sense can be "measured" by a questionnaire developed by the author (sense of coherence; hereinafter, SOC) or its more recent versions, prepared by the advocates of holistic medicine (SOC II, SOCE) [57,58]. Utilization of these questionnaires before and after interventions intended to improve health turned out to be very useful. For example, in the field of work, the version of this questionnaire which measures workers' organizational engagement is used among others; Organizational Engagement (OE) is applicable in the processes of assessment and choosing adequate profile of workers for different job positions in companies to improve business results. Work organization largely determines the quality of life (health) of the employees. Therefore, this is an important, but not the only instrument in the process of health promotion at workplace and realization of the stress-relieving program [59]. Also, it can be useful for professional selection, orientation, re-orientation and certification of older workers to confirm their ability to continue their jobs [60].

Detailed description of salutogenesis, or holistic medicine for that matter, although necessary for better understanding of the problems discussed hereinafter, goes beyond the scope of this paper. Nonetheless, some rudiments are necessary. This is the case because salutogenesis and holistic medicine are envisaged by the WHO's plan in the part that urges for the actions for health promotion at workplace, and because it is as an initiation of continual education regarding the mentioned topic within the profession in question.

Such holistic approach toward workers' health is possibly a unique opportunity of occupational health as vocation in Serbia to defend, survive, grow stronger and take initiative in the most important field which, besides the advantage of improving the condition of a population, may have the more important economic impact: decreasing of expenditure for more and more costly conventional medical care and employing of considerable number of young people to implement a new (holistic) concept in medical care $[61,62]$.

\section{HOLISTIC MEDICINE OR BIOMEDICINE}

As natural science, especially chemistry, developed a long list of pharmaceutical drugs that became available to the physician in the 20th century, many medical schools accepted biomedicine as the dominant type of medicine, while other kinds of medicine were defined as "alternative" [63]. The cost-effectiveness of medicine has become an important issue as the costs of biomedicine in many countries have become an economically enormous burden. In countries with social healthcare system, biomedicine is often the dominating kind of medicine for a population, 
where half the citizens are being chronically ill. The national cost of the pharmaceuticals had been doubling every five years for two decades in many European countries, and the trend seems to continue. Also, there has been an increasing awareness of lack of efficiency and high incidence of side effects and adverse events in pharmacological medicine, which has created a renewed interest in the classical non-pharmacological medicine. Therefore, less expensive holistic, complementary and alternative medicine (CAM) treatments have become the focus of attention, as these treatments might be more cost-effective than biomedicine $[64,65]$.

The western tradition of scientific medicine started in Greece 400 BCE, where the physician Hippocrates and his students had a hospital on the island of Cos. The original writings are preserved as the Hippocratic Corpus. The medicine of Hippocrates was holistic as it intervened on all aspects of man — body, mind and spirit — at the same time. For over 2000 years this medicine was practiced all over Europe almost completely without the use of drugs. Its fundamental idea was to induce salutogenesis i.e. "healing of the patient's whole life and existence" by helping the patient to increased self-insight. This was done through the concept of talents and character. When the patient understood him- or herself and was able to use all talents - "bodily, mental and spiritual" - to create value to self and others, he or she recovered the sense of coherence (SOC), and improved quality of life, health, and ability. This route of "quality of life as medicine" or personal development for health is the fundamental principle of CAM today. Also low working ability was efficiently solved with CAM [63].

In the future it will not be enough for a physician just to prescribe drugs. In the future, patients will be better informed and they will want more from their doctor. They will want a medicine that is likely to cure them. For some clinical conditions like acute infections, future medicine might still be an antibiotic drug, but for most clinical conditions the medicine to cure patients in the future is likely to be a non-drug medicine (CAM) [66].

In the history of medicine, the commercial interests have often trumped science, and we need to learn from that so we can make medicine more rational in the future [67]. Money now used on inefficient biomedicine could be used to solve some of the true problems of the world. A more healthy population would also take better care of the planet and of each other, making the world a better place. The final say about which kind of medicine we shall have in this world will hopefully come from people who take care of the patients' best interest, not the interests of the industry and its allies, and who unbiased will analyze which medicine is the most helpful for the patients. It basically boils down to the matter of cost efficacy: How much health and healing can I as a patient buy for one dollar, pound, or euro? [64].

\section{CONCLUSION}

Each society has been facing not only a probable and possible future, but also the problem of desired future. Directing development means making an effort to transform that possible future from a desired one into a probable one. Whether the occupational health will exist tomorrow, or whether its development will be directed to holistic medicine, depends on each individual employee of the institutions connected with it. In a way, everybody may contribute to survival and development of the vocation, taking it to even better direction. Great responsibility is given to professors of occupational health at all universities in the country, regarding implementation of scientificallyproven methods for realization of the vision of vocation, as well as new curricula within the course they can indisputably alter. Many segments of desirable vision deserve to be a topic of future interdisciplinary projects, term papers, doctoral, specialist and degree thesis. Without young professionals, educated and qualified in the said filed, the 
vision "A healthy worker at a healthy workplace" may not go beyond a good motto.

When it comes to workers' health in Serbia, the hardest issue to talk about is the responsibility of other subjects in the context of obligatory three-partite approach. We may only hope that it will not fail to take place.

\section{ACKNOWLEDGEMENTS}

This study was published thanks to the Ministry of Science and Technological Development of the Republic of Serbia (Project No. III-43014 and Project No. 42008).

\section{REFERENCES}

1. WHO. Global Plan of Action on Workers' Health for 2008-2017 (adopted in 2007) [cited 2010 Jun 21]. Available from URL: http://www.who.int/gb/ebwha/pdf_files/EB120/B120_28Rev1en.pdf

2. WHO. Global Network of Collaborating Centres in Occupational Health (2009). Work Plan 2009-2012 [cited 2010 Jul 15]. Available from URL: http://www.who.int/occupational_health/cc_compendium.pdf.

3. WHO: Healthy Workplace Framework: Background and Supporting Literature and Practices (2010) [cited 2010 Jun 3]. Available from URL: http://www.who.int/occupational_health/ healthy_workplaces/en/index.html.

4. WHO. Global Plan of Action on Workers' Health, 2008-2017. Sixtieth World Health Assembly. Sixth Meeting of the South East European Network on Workers' Health; 2010 Jun 27-30; Grožnjan, Croatia [cited 2010 Sep 15]:[8 screens]. Available from URL: http://apps.who.int/gb/ebwha/pdf_files/ WHA60/A60_R26-en.pdf.

5. Mostert K. The balance between work and home: The relationship between work and home demands and ill health of employed females. SA J Ind Psychol 2009 [cited 2010 Jun 7];31(1): [8 screens]. Available from URL: http://www.sajip.co.za/index.php/sajip/article/view/743/854.
6. Godin I, Kittel F. Differential economic stability and psychosocial stress at work: associations with psychosomatic complaints and absenteeism. Soc Sci Med 2004;58(8):1543-53.

7. Soren VG, Trine FM, Niels JA, Michael N, Morad M, Joav M. Global Quality of life (QOL), health and ability are primarily determined by our consciousness. Research findings from Denmark 1991-2004. Soc Indicators Res 2005;71:87-122.

8. Eriksson M, Lindstrom B. Antonovsky's Sense of Coherence Scale and its relation with quality of life: A systematic review. J Epidemiol Community Health 2007;61:938-44.

9. Lent W, Singley D, Sheu B, Gainor A, Brenner R, Treistman $\mathrm{D}$, et al. Social cognitive predictors and life satisfaction: Exploring the theoretical precursors of subjective well-being. J Couns Psychol 2005;52:429-42.

10. Ventegodt S, Morad M, Kandel I, Merrick J. Clinical holistic medicine: social problems disguised as illness. Sci World J 2004;4:286-94.

11. Ventegodt S, Morad M, Hyam E, Merrick J. Clinical holistic medicine: when biomedicine is inadequate. Sci World J 2004;4:333-46.

12. Ventegodt S, Morad M, Kandel I, Merrick J. Clinical holistic medicine: a psychological theory of dependency to improve quality of life. Sci World J 2004;4:638-48.

13. Ventegodt S, Morad M, Kandel I, Merrick J. Clinical holistic medicine: problems in sex and living together. Sci World J 2004;4:562-70.

14. Ventegodt S, Morad M, Hyam E, Merrick J. Clinical holistic medicine: holistic sexology and treatment of vulvodynia through existential therapy and acceptance through touch. Sci World J 2004;4:571-80.

15. Ventegodt S, Kandel I, Neikrug S, Merrick J. Clinical holistic medicine: the existential crisis - life crisis, stress, and burnout. Sci World J 2005;5:300-12.

16. Frankl Viktor E. Man's Search for Meaning: An introduction to Logotherapy, Preface by Gordon W. Allport. London: Hodder\&Stoughton; 1964.

17. Frankl Viktor E. On Logotherapy and existential analysis. Am J Psychoanal 1958;18:28-37. 
18. HSE. Health and Safety Executive: What are the Management Standards, Essentials of health and safety at work [cited 2010 Jun 7]. Available from URL: http://www.hse.gov.uk/aboutus/ index.htm.

19. Arandjelovic M, Ilic I. Stress in workplace - possible prevention. Facta Univ Ser Med Biol 2006;13(3):139-44.

20. Breslow L. Health measurement in the third era of health. Am J Pub Health 2006;96(1):17-9.

21. Byrne D. Enabling good health for all: A reflection process for a new EU health strategy. European Commission; 2004 [cited 2010 Jun 29]. Available from URL: http:// ec.europa.eu/health/ph_overview/Documents/pub_good_ health_en.pdf

22. Arandjelovic M, Milic I, Radevic Lj, Lekovic S, Gavrilovic V, Nikolic V. Healthy work in the ageing Europe. Acta Med Medianae 2008;47(4):34-8.

23. Arandjelovic M, Radevic L. International code of ethics for occupational health professionals in Serbia. World Work 2008;5(6):601-704 [in Serbian].

24. Arandjelovic M, Radevic Lj, Todorovic Z, Lekovic S. Promotion of prevention culture - occupational medicine task. World Work 2008;6(1):25-42 [in Serbian].

25. Shahtahmasebi S. The good life: A holistic approach to the health of the population. Sci World J: TSW Holist Health Med 2006;6:2117-32.

26. Shahtahmasebi S. Quality of life: A case report of bullying in the workplace. Sci World J 2004;4:118-23.

27. Arandjelovic M, Antic M, Kocic B. Ethical problems of medical care for employees during transition. TEME 2008;4: 811-23 [in Serbian].

28. Arandjelovic M, Stankovic S. Workplace health promotion - quality criteria. Facta Univ Ser Work Living Environ Prot 2006;3(1):27-33.

29. Ventegodt S, Anderson NJ, Merrick J. Quality of life philosophy: when life sparkles or can we make wisdom a science? Sci World J 2003;3:1160-3.

30. Ventegodt S, Merrick J. Clinical holistic medicine: applied consciousness-based medicine. Sci World J 2004;4:96-99.
31. Ventegodt S, Morad M, Merrick J. Clinical holistic medicine: classic art of healing or the therapeutic touch. Sci World J 2004;4:134-47.

32. Ventegodt S, Morad M, Merrick J. Clinical holistic medicine: holistic pelvic examination and holistic treatment of infertility. Sci World J 2004;4:148-58.

33. Ventegodt S, Morad M, Merrick J.Clinical holistic medicine: the "new medicine", the multiparadigmatic physician, and the medical record. Sci World J 2004;4:273-85.

34. Ventegodt S, Morad M, Hyam E, Merrick J. Clinical holistic medicine: use and limitations of the biomedical paradigm. Sci World J 2004;4:295-306.

35. Ventegodt S, Morad M, Andersen NJ, Merrick J. Clinical holistic medicine: tools for a medical science based on consciousness. Sci World J 2004;4:347-61.

36. Ventegodt S, Morad M, Hyam E, Merrick J. Clinical holistic medicine: induction of spontaneous remission of cancer by recovery of the human character and the purpose of life (the life mission). Sci World J 2004;4:362-77.

37. Ventegodt S, Morad M, Kandel I, Merrick J. Clinical holistic medicine: treatment of physical health problems without a known cause, exemplified by hypertension and tinnitus. Sci World J 2004;4:716-24.

38. Ventegodt S, Solheim E, Saunte ME. Morad M, Kandel I, Merrick J. Clinical holistic medicine: metastatic cancer. Sci World J 2004;4:913-35.

39. Ventegodt S, Morad M, Merrick J.Clinical holistic medicine: developing from asthma, allergy, and eczema. Sci World J 2004;4:936-942.

40. Ventegodt S. Merrick J. Clinical holistic medicine: chronic infections and autoimmune diseases. Sci World J 2005;5: $155-64$.

41. Ventegodt S. Merrick J. Clinical holistic medicine: chronic pain in the locomotor system. Sci World J 2005;5:165-72.

42. Ventegodt S. Merrick J. Clinical holistic medicine: chronic pain in internal organs. Sci World J 2005;5:205-10.

43. Ventegodt S, Gringols M, Merrick J. Clinical holistic medicine: holistic rehabilitation. Sci World J 2005;5:280-87. 
44. Ventegodt S, Andersen NJ, Neikrug S, Kandel I, Merrick J. Clinical holistic medicine: mental disorders in a holistic perspective. Sci World J 2005;5:313-23.

45. Ventegodt S. Merrick J. Clinical holistic medicine: the patient with multiple diseases. Sci World J 2005;5:324-39.

46. Ventegodt S, Andersen NJ, Neikrug S, Kandel I, Merrick J. Clinical holistic medicine: holistic treatment of mental disorders. Sci World J 2005;5:427-45.

47. Ventegodt S, Clausen B, Nielsen ML, Merrick J. Advanced tools for holistic medicine. TSW Holistic Health Med 2006;1:84-101.

48. Ventegodt S, Merrick E, Merrick J. Clinical holistic medicine: the Dean Ornish program ("opening the heart") in cardiovascular disease. TSW Holist Health Med 2006;1:13-20.

49. Antonovsky A. The salutogenic model as a theory to guide health promotion. Health Promot Int 1996;11:11-8.

50. Lindstrom B, Eriksson M. Contextualising salutogenesis and Antonovsky in public health. Health Promot Int 2006;21: 238-44.

51. Arandjelovic M, Ilic I, Jovic S. Burnout and the quality of life of workers in food industry - A pilot study in Serbia. Vojnosanit Pregl 2010;67(9):705-11 [in Serbian].

52. Morgan A. Ziglio E. Revitalising the evidence base for public health: an assets model. Promot Educ 2007;2:17-22.

53. Eriksson M, Lindstrom B. Antonovsky's Sense of Coherence Scale and the relation with health - a systematic review. J Epidemiol Community Health 2006;60:376-81.

54. Eriksson M, Lindstrom B. Validity of Antonovsky's Sense of Coherence Scale - a systematic review. J Epidemiol Community Health 2005;59:460-6.

55. Antonovsky A. Breakdown: a needed fourth step in the armamentarium of modern medicine. Soc Sci Med 1972;6:537-44.

56. Dooris M. Healthy settings: challenges to generating evidence of effectiveness. Promot Int 2005;21(1):55-66.

57. Binder HP, Mesenholl-Strehler E, Paß P, Endler PC. Sense of coherence (SOC) among psychotherapists in Austria, differentiated according to number of individually completed training therapy session. TSW Holist Health Med 2006;1:232-5.
58. Ventegodt S, Thegler S, Andreasen T, Struve F, Enevoldsen L, Bassaine L, et al. Clinical holistic medicine (mindful, short-term psychodynamic psychotherapy complemented with bodywork) improves quality of life, health, and ability by induction of Antonovsky-Salutogenesis. TSW Holist Health Med 2007;7:317-23.

59. Endler PC, Haug TM, Spranger H. Sense of coherence and physical health. A "Copenhagen interpretation" of Antonovsky's SOC concept. Sci World J 2008;8:451-3.

60. Becker C, Glascoff MA, Felts WM. Salutogenesis 30 Years Later: Where do we go from here? Int Electr J Health Educ 2010;13:25-32.

61. Netuveli G, Blane D. Quality of life in older ages. Br Med Bull 2008;85:113-26.

62. Arandjelovic M, Nikolic M, Stamenkovic S. Relationship between burnout, quality of life, and work ability index - directions in prevention. Sci World J 2010;10:766-77.

63. Ventegodt S, Andersen NJ, Kandel I, Merrick J. Effect, side effects and adverse events of non-pharmaceutical medicine. A review. Int J Disabil Hum Dev 2009;8(3):227-35.

64. Ventegodt S, Andersen NJ, Kandel I, Merrick J. Comparative analysis of cost-effectiveness of non-drug medicine (nonpharmaceutical holistic, complementary and alternative medicine/CAM) and biomedicine (pharmaceutical drugs) for all clinical conditions. Int J Disabil Hum Dev 2009;8(3):243-58.

65. Ventegodt S, Merrick J. A Review of Side Effects and Adverse Events of Non-Drug Medicine (Nonpharmaceutical Complementary and Alternative Medicine): Psychotherapy, Mind-Body Medicine and Clinical Holistic Medicine. J Complement Integr Med 2009;6(1): Art. 16. DOI: 10.2202/1553-3840.1156.

66. Ventegodt, S., Merrick, J. Therapeutic value (TV) of alternative medicine (non-drug CAM). Rough estimates for all clinical conditions based on Cochrane reviews and the ratio: Number Needed to Harm/Number Needed to Treat (TV=NNHtotal/NNT). BMJ 2010 [cited 2010 Nov 25]. Available from URL: http://www.bmj.com/content/341/bmj. c5715.full/reply\#bmj_el_244740. 
67. Ventegodt, S., Merrick, J. Therapeutic value (TV) of treatments with pharmaceutical drugs. Rough estimates for all clinical conditions based on Cochrane reviews and the ratio: Number Needed to Harm/Number Needed to Treat (TV=NNHtotal/
NNT). BMJ 2010 [cited 2010 Nov 25]. Available from URL: http://www.bmj.com/content/341/bmj.c5715.full/reply\#bmj_ el_244738.

This work is available in Open Access model and licensed under a Creative Commons Attribution-NonCommercial 3.0 Poland License - http://creativecommons.org/ licenses/by-nc/3.0/pl/deed.en. 